\title{
El ocaso de los conquistadores: los límites de la riqueza y la lealtad durante la rebelión de los encomenderos en el virreinato del Perú, 1544- $1548^{1}$
}

\section{The decline of the conquerors: the limits of wealth and loyalty during the rebellion of the encomenderos in the viceroyalty of Peru, 1544-1548}

Alfredo Luis Escudero Villanueva²
Pontificia Universidad Católica del Perú

\section{Resumen}

Se explica el fracaso de la rebelión de los encomenderos (1544-1548), liderada en el virreinato del Perú por Gonzalo Pizarro contra las autoridades reales, a partir del deterioro de la producción y la riqueza en esos años. Si bien el líder rebelde pudo inicialmente sostener una guerra, el deterioro de las encomiendas, asociado a la reducción de la mano de obra indígena, al empobrecimiento de la producción y sumado a la molestia de los vecinos y encomenderos por el impacto

1 Este artículo está basado en mi tesis sustentada en la Pontificia Universidad Católica del Perú. La tesis completa puede ser leída en el siguiente enlace: http://tesis.pucp.edu.pe/repositorio/handle/123456789/8326

2 Licenciado en historia por la Pontificia Universidad Católica del Perú. Código ORCID: 0000-0003-2000-9267

Contacto: alfredo.escuderov@pucp.pe 
negativo que la guerra tenía sobre sus riquezas, erosionaron la autoridad de Gonzalo Pizarro y el movimiento rebelde.

Palabras clave: Conquista, encomienda, rebelión de los encomenderos, Gonzalo Pizarro, Perú, siglo XVI

\section{Abstract}

The defeat of the encomenderos' rebellion (1544-1548), led in the viceroyalty of Peru by Gonzalo Pizarro against the Spaniard crown is described, emphasizing its failure due to the economic stagnation in that period. At the beginning of the rebellion, Gonzalo Pizarro was able to establish control over the territory and its resources. However, the decrease of indigenous labor and the encomienda's production added to the annoyance of neighbors and encomenderos caused by the negative impact of the war and undermined Pizarro's authority and the rebel movement.

Key words: Conquest, encomienda rebellion, Gonzalo Pizarro, Perú, XVI century

Entre 1544 y 1548, en pleno proceso de conquista y colonización de América del Sur, sucedió un conflicto que puso

112 en riesgo el proyecto de expansión colonial y la vida de los habitantes del Nuevo Mundo. Un gran grupo de encomenderos en el virreinato del Perú se rebeló contra las órdenes de Carlos I y la aplicación de las Leyes Nuevas ${ }^{3}$, que dismi-

3 Las Leyes Nuevas fueron un conjunto de ordenanzas promulgadas en 1542 por Carlos I de Castilla que permitían regular las encomiendas y mejorar el trato de la población indígena de los nuevos territorios con- 
nuían el poder que tenían los conquistadores-encomenderos en beneficio de nuevas autoridades e instituciones coloniales. Los rebeldes tomaron estas leyes por injustas y su rechazo promovió un conflicto armado entre dos bandos: el realista, liderado primero por el virrey Blasco Núñez Vela y luego por Pedro de la Gasca; y el rebelde, liderado por Gonzalo Pizarro, bando que fue derrotado. El conflicto comprometió los recursos económicos y a los distintos actores sociales del virreinato durante cuatro ańos.

Pese a la relevancia que tuvo este movimiento, poco se ha estudiado desde el punto de vista de los intereses de sus actores sociales y cómo estos se fueron modificando a través del conflicto $^{4}$. La historiografía ha mantenido un enfoque político para explicar el desenlace de la rebelión ${ }^{5}$. En este estudio, propongo tomar la primera ruta y revelar cómo los intereses de los grupos sociales de la temprana colonización en el Perú impactaron en la derrota del movimiento. Para ello, es ne-

quistados. Uno de los principales promotores de estas ordenanzas fue Bartolomé de las Casas, quien defendía la reducción del poder de los conquistadores en beneficio de la población nativa y de la misión evangelizadora de la Iglesia.

4 Uno de los trabajos que anunciaba la importancia de este enfoque fue el de Bataillon (1995, p. 79). Una publicación más reciente es la de Drigo (2006).

5 Lohmann Villena ha señalado: «(...) Gonzalo Pizarro acusó de un error supremo en un caudillo: no tener los pies bien asentados en la realidad, al desconocer unas convicciones inmutables que a su turno facilitaron el triunfo de Gasca: el sentimiento monárquico y el respeto por la institución, en tiempos en que Carlos $\mathrm{V}$ era la más nítida imagen de la noción imperial como representante históricamente legítimo del poder: potestas y auctoritas» (Lohmann, 1977, p. 20.). Es decir, el compromiso con el proyecto de la monarquía fue causa de la derrota rebelde. 
El ocaso de los conquistadores: los límites de la riqueza y la lealtad durante la rebelión de los encomenderos en el virreinato del Perú, 1544-1548

cesario describir brevemente los principales acontecimientos del periodo y, luego, analizar a los actores que participaron en el conflicto.

El inicio del conflicto se vincula con la promulgación de las Leyes Nuevas en 1542 por parte de la Corona de Castilla, pero su aplicación estaba programada para cuando el virrey Blasco Núñez Vela llegase en 1544 al recientemente creado Virreinato del Perúc . Como se ha señalado, una razón esencial del gran descontento que generó fue la restricción a la encomienda, es decir, a la mano de obra indígena (Bataillon, 1985, p. 83). Luego de intentos infructuosos de negociar con el virrey, los conquistadores y encomenderos promovieron el uso de la fuerza y distintos cabildos pidieron que Gonzalo Pizarro, hermano del fallecido Francisco Pizarro, lidere la oposición con el título de gobernador ${ }^{7}$. Mientras el virrey huyó a Quito, desde donde comandó sus tropas, el nuevo gobernador Pizarro se estableció en Lima y tuvo el apoyo de la mayoría de encomenderos del territorio.

El movimiento rebelde demostró rápidamente ser una amenaza contra los planes de la Corona. En 1546 se produjo la batalla de Ińaquito, donde murió el virrey y quedó Gonzalo Pizarro como máxima autoridad del virreinato peruano, incluso por encima de los oidores. Los circuitos comerciales,

114 la mano de obra indígena, los soldados y gran parte de los recursos del territorio estaban bajo la autoridad directa de

6 En 1542 se oficializó el nombre de Virreinato del Perú y, aunque muchos protagonistas del periodo se referían a esta como "gobernación», se usará el término oficial de virreinato.

7 Para detalles de la ascensión política de Gonzalo Pizarro de capitán a gobernador, sugiero revisar Lohmann (1977). 
Pizarro y sus tenientes, y no bajo autoridad del rey o sus representantes. Como parte de los esfuerzos por expandir el control de la región, la ciudad de Panamá, parada obligada para quienes se dirigían al virreinato peruano, llegó a ser atacada por la flota rebelde y brevemente controlada hacia 1545. Durante estos dos primeros ańos, Gonzalo Pizarro y sus aliados demostraron que podían frenar cualquier intento de reforma real que no contase con el apoyo de los encomenderos y que su presencia era un obstáculo para el proyecto de la monarquía castellana expresado en las Leyes Nuevas.

La respuesta de la Corona no se hizo esperar y el conflicto pasó a una segunda etapa. En 1546 fue enviado el pacificador Pedro de la Gasca con la facultad de ejercer el "perdón real" a los rebeldes y con el anuncio de que los perjuicios generados por las Leyes Nuevas iban a ser revocados. En 1547, el pacificador llegó a las costas de Manta y desde allí planeó su avance hacia el sur. En paralelo, ese año se produjo la batalla de Huarina entre un grupo de fuerzas rebeldes lideradas por Francisco de Carvajal y los leales a la Corona, liderados por Diego Centeno, quienes fueron derrotados. Sin embargo, este conflicto fue el síntoma de un descontento general contra el gobierno liderado por Pizarro. Distintos aliados rebeldes fueron progresivamente plegando su voluntad a la Corona hasta el enfrentamiento de Jaquijahuana o Xaquijahuana en 1548, donde Gonzalo Pizarro, muy venido a menos en tropas, perdió aplastantemente contra las fuerzas del pacificador. Un reparto de dinero, llamado «reparto de Guaynarima», se realizó entre los fieles a la Corona. A partir de ese momento, Pedro de la Gasca tomó el gobierno del virreinato y se establecieron 
las instituciones coloniales con mayor solidez .

Sobre el desarrollo de la rebelión, cabe preguntarse: ¿por qué un personaje que concentró el poder del virreinato peruano en 1544 fue derrotado tan fácilmente tres años después? Lo que conduce también a cuestionarse qué pasó con los encomenderos y otros actores que inicialmente impulsaron un enfrentamiento contra el virrey, pero terminaron aceptando al pacificador. Esto lleva a analizar los vínculos de lealtad y los cambios de las expectativas sociales que sufrió la sociedad colonial en esos años.

En las siguientes páginas, propongo como explicación que la derrota de la rebelión estuvo ligada al deterioro de las condiciones materiales del virreinato, en particular de la encomienda. Primero, relevaré la importancia que tenía la encomienda en ese periodo para la formación de alianzas y luego me centraré en el empobrecimiento como explicación al deterioro que atravesaba la rebelión. Más adelante, me enfocaré en cómo este deterioro progresivamente causó el abandono de los aliados rebeldes y perfiló la derrota del movimiento a la llegada de Pedro de la Gasca. El incumplimiento de las expectativas materiales, que no solo se refieren a la obtención de encomiendas, sino también de dinero o cargos fue clave para la pérdida de liderazgo del último de los Pizarro en los

116 Andes.

\section{Conquistar y gobernar en el Nuevo Mundo}

La obtención de riqueza siempre fue un móvil central durante el proceso de conquista. Esto se puede rastrear desde los

8 Sobre el proceso de asentamiento de las instituciones coloniales posterior a este periodo, véase Bakewell, 1989, pp. 41-70. 
primeros baquianos y colonos que se aventuraron en la conquista del territorio americano, con énfasis en la expedición de Hernán Cortés, donde quedaba demostrado que la conquista podía ofrecer grandes beneficios a sus participantes? Durante las primeras décadas de conquista en el continente, las expectativas por encontrar riquezas motivaron expediciones entre grupos de conquistadores, cuyo fin era mejorar su estatus social y su patrimonio personal (Thorton, 2012, pp. 186-187 ${ }^{10}$. El cumplimiento central de estas expectativas recaía principalmente en la posesión de las encomiendas, sobre las cuales, además, debía fundarse la sociedad colonial, con los encomenderos a la cabeza (Elliott, 2008, pp. 72-73). Luego, los conquistadores convertidos en prósperos encomenderos debían encargarse de cimentar las bases institucionales que permitiesen la integración de la población indígena, proceso en el que la evangelización tenía gran importancia. Al respecto, Seed (1995, p. 70) señala la preocupación en extender la evangelización como estrategia para anexar el nuevo territorio a la monarquía castellana luego del proceso militar de la conquista.

Sin embargo, un tema que merece mayor atención es la forma en que se construyó el primer orden colonial a partir de la distribución de recursos durante el proceso de conquista. John Elliott ha descrito el sistema patrimonial como una ló-

9 Hacia 1530, una treintena de encomenderos administraba una población de 180.000 mil indios de quienes recibían el tributo respectivo (Hamnett 2001).

10 Según Thorton, la primera recompensa esperada de la conquista era un pago estable a través de la encomienda y el tributo indígena. Luego, estos encomenderos y conquistadores tuvieron la posibilidad de realizar empresas de agricultura y minería, entre otros. 
gica de distribución por la cual el rey entregaba cargos, mercedes y honores entre quienes le rendían servicios (Elliott, 1990, p. 132). A partir de esta noción, propongo resaltar que durante la conquista este poder no lo ejerció el rey directamente, sino el líder de la expedición conquistadora convertido luego en gobernador. Esto generó que sea el líder del grupo de conquistadores, el principal encargado de distribuir recursos o cargos. A medida que los conquistadores fueron cercanos a estos líderes, mayores beneficios recibieron de las expediciones.

De la misma manera, Gonzalo Pizarro, con el título de gobernador, se encargó de distribuir dinero, cargos y, sobre todo, encomiendas entre los distintos aliados que sustentaban el movimiento ${ }^{11}$. El control de los recursos fue una de las principales preocupaciones que tuvo el líder a lo largo de los años del movimiento y mostró también el aspecto más débil de los conquistadores, quienes habían llegado a luchar, pero no dominaron el arte de gobernar. En 1547, Pizarro escribió a Pedro de Soria: "en su carta bien parece que está lexos, pues no entiende pensando a los que tengo de dar de comer y vestir, que lo están aguardando" (Pérez de Tudela, 1964, t. I, p. 91). Efectivamente, múltiples cartas del periodo comunicaban distintas exigencias que soldados y encomenderos le hacían al líder rebelde.

11 Para este momento, Gonzalo Pizarro gozaba de las fuentes de riqueza del territorio, como dinero de las cajas reales o tributos de encomiendas, además de la riqueza acumulada por sus hermanos. Sobre este último punto, él heredó gran parte de esta riqueza como resultado de la conquista dirigida por su hermano mayor Francisco Pizarro. El análisis de esta empresa es realizado por Rafael Varón (1997), quien pone de manifiesto los esfuerzos que realizaron los hermanos Pizarro en su carrera de enriquecimiento en el Nuevo Mundo. 
De esta manera, se revela que un elemento central para la formación de una alianza entre los encomenderos y otros actores alrededor de Pizarro fue la distribución de los recursos. El imperio de los incas había legado una gran cantidad de riqueza, sobre todo, una gran cantidad de población por repartir hacia la década de 1540. Los encomenderos del territorio buscaban asegurar lo ganado, mientras los no encomenderos buscaron ganar beneficios con su acercamiento a Pizarro y su oposición al virrey. De esta manera, el liderazgo pizarrista se sostuvo por su capacidad de brindar protección al patrimonio material del virreinato y distribuirlo correctamente ${ }^{12}$.

El contexto no era favorable cuando el nuevo gobernador del virreinato peruano se embarcó en la labor de gobernar, puesto que la conquista como medio de acumular riqueza presentaba un freno importante en 1544 (Chaunu, 1973, p. 39). Esta situación se reveló luego de los fracasos de las expediciones de Gonzalo Pizarro en búsqueda del país de la canela (1540), ya que Pedro de Valdivia en Chile (1541) y Juan de Ponce en los Bracamoros (1536-1543) no encontraron ni grandes riqueza, ni mano de obra indígena significativa. Por ello, en el caso peruano, quienes buscaban su promoción social, debían apuntar sus esfuerzos en ser beneficiados con las riquezas y encomiendas que ya existían en el virreinato. Como lo ha señalado Lockhart, (1982, p. 25), una forma de

12 Sugiero analizar la capacidad de liderazgo de Pizarro cuando el ejercicio del poder recaía en su persona. Un autor que ha ofrecido una mirada sobre la construcción del liderazgo en rebeliones ha sido Barrington Moore (1989, p. 33). Aunque su análisis se centró en periodos más contemporáneos, su análisis resulta conveniente para contextos cronológicos anteriores. 
El ocaso de los conquistadores: los límites de la riqueza y la lealtad durante la rebelión de los encomenderos en el virreinato del Perú, 1544-1548

salir de este problema fueron las guerras civiles entre conquistadores, pues el reparto de encomiendas estaba estrechamente ligado al resultado de las guerras, de ahí que los involucrados hayan estado interesados en apostar por quien mostrase una mejor posición en el conflicto, de tal forma que saliesen beneficiados. A raíz de estos intereses manifestados en los conflictos entre conquistadores, es que durante la rebelión de los encomenderos distintos actores sociales plegaron su lealtad a Gonzalo Pizarro, quien acumulaba la riqueza del virreinato y se articuló en una red de aliados que permitiese sustentar el movimiento rebelde.

Ya que la distribución de la riqueza giraba en torno a Pizarro, también era su responsabilidad la administración y organización del territorio en esos años de guerra. Para ello, el líder rebelde contó con el apoyo de un conjunto de tenientes ${ }^{13}$, quienes tenían la función de distribuir o quitar encomiendas entre los amigos y enemigos de la rebelión, y con el amparo de Pizarro, realizar derramas para obtener fondos en favor de la rebelión ${ }^{14}$, derivar armas y soldados a la guerra, coordinar

13 La lista inicial de tenientes es la siguiente: Alonso de Toro en Cusco, Lorenzo de Aldana en Lima, Hernando de Alvarado en Piura, Francisco de Almendras en La Plata, Pedro de Fuentes en Arequipa, Francisco de Cárdenas en "Guamanga", Diego de Carvajal en "Guanuco», Diego de Mora en Trujillo, Gómez de Alvarado en Chachapoyas y, una vez muerto el virrey, Pedro de Puelles en Quito. Por deserción o muerte, algunos de estos nombres cambiaron hacia 1547. Es el caso de Lucas Martínez Vegazo, quien reemplazó a Fuentes en la ciudad de Arequipa.

14 La derrama era la recolección de dinero o cupos para el financiamiento de la guerra que se realizaba en las ciudades y se apelaba a la colaboración de los vecinos. Rafael Loredo ha publicado la derrama del Cuzco a inicios de ese periodo, en la que se indica la cantidad de pesos asignada por cada vecino (Loredo, 1942, pp. 297-301). Carvajal hizo una derrama en 
el trabajo indígena en el movimiento y ejercer justicia según las necesidades que presentaba el conflicto. Su contacto directo con los vecinos y la realidad de cada ciudad es clave para comprender la evolución del movimiento rebelde.

El carácter fuertemente personalista de este movimiento se puso de relieve desde muy temprano. Gonzalo Pizarro delegaba en sus tenientes y capitanes la administración, pero no compartía su poder con las instituciones coloniales. Los miembros del cabildo de Lima se volvieron dependientes de la protección de Pizarro mientras les enviaba los recursos de la caja real, al igual que lo hicieron otros cabildos. La Audiencia intentó someter al líder rebelde luego de su llegaba al virreinato ${ }^{15}$, pero rápidamente fueron abolidos y el oidor Diego Vázquez de Cepeda se volvió un gran aliado pizarrista durante la rebelión. En suma, las débiles instituciones quedaron subordinadas a la autoridad de Pizarro.

Las fuentes del periodo también destacan el apoyo de la mano de obra indígena, especialmente de los curacas, para distintas gestiones logísticas que implicaba la movilización de población indígena. Por ejemplo, mientras las fuerzas pizarristas perseguían al virrey a través del desierto, se dio «orden como los indios comarcanos llevasen agua y comida necesaria, así para la gente como para los caballos» (Fernández 1963, t. I,

Huamanga en 1545 (Rivera, 1966, p. 174) y otra en Lima en 1546 (De las Casas, 2003, p. 255).

15 Los oidores le escribieron a Pizarro cuando avanzaba con sus tropas sobre Lima: «Por la presente vos mandamos que, luego questa nuestra carta veáis, deshagáis et mandéis deshacer todo el exército et gente de guerra que con vos traéis... vengáis a la dicha ciudad de los Reyes, a la dicha nuestra real Audiencia que en ella reside...» (Pérez de Tudela, t. I, pp. 328-329). El mensaje no tuvo efecto. 
p. 68). Por otro lado, la población indígena podía ser clave en las comunicaciones y en la transmisión de noticias. Durante su campaña en Quito contra Gonzalo Pizarro, el virrey se enteró del acercamiento de Gonzalo Pizarro gracias a un capitán indio, posiblemente un curaca, llamado Yllatopa (Zárate, 1995, p. 31). En otro momento, desde el Cuzco, el capitán Pedro de Bustinça mandó a los indios que arreglen el puente de "Apurima» con sogas "cabuya» (Loredo, 1943, pp. 71-72). De esta manera, el apoyo logístico de la población indígena fue constante en el desarrollo del conflicto.

Es conveniente destacar que el principal sustento económico del movimiento era el tributo generado por la mano de obra indígena. Cuando Francisco de Almendras, teniente en Las Charcas, asumió su cargo, «lo primero que hizo fue llamar a todos los caciques y principales indios de todo aquel distrito y juridición» (Gutiérrez de Santa Clara, 1963, p. 250) con la orden de destinar los tributos hacia su persona. En la misma región, Gonzalo Pizarro cobraba el dinero de los repartimientos que se quitaron a los detractores de la rebelión y que puso "bajo su cabeza" con el fin de sustentar sus gastos de guerra (Zárate, 1995, p. 229).

Por ello, no es de sorprender que se hayan anunciado medidas de protección indígena en esos años. El cabildo de

122 Huamanga, hacia 1545, ordenó que ningún vecino saliese de la ciudad sin permiso del gobernante o teniente con el fin de evitar agravios contra la población nativa (Rivera, 1996, p. 145). Todo ello pone de manifiesto la importancia de la mano de obra indígena, gestionada a través de los encomen- 
deros, tenientes y $\operatorname{curacas}^{16}$, en el desarrollo de la guerra y en su desenlace, como se verá más adelante.

Otro grupo importante en este proceso fueron los soldados contratados para luchar en este conflicto, cuya participación era central para mantener la guerra. Según las fuentes, los soldados estaban distribuidos en el territorio y había que incorporarlos a la tropa rebelde. En la zona de Jauja se realizó un reclutamiento para agrupar a un conjunto de soldados entre arcabuceros, caballeros y piqueros, pero también "otra mucha gente que cada día se recoge y está esperando por los caminos" (De las Casas, 2003, p. 310). Lejos de las posiciones de privilegio que tenían los tenientes y encomenderos, la actuación de estos soldados también nos permite comprender el desarrollo de este conflicto.

En teoría, los soldados podían seguir las expectativas de enriquecimiento de los conquistadores, pero en la práctica la mayoría no lograba su cometido. En una comunicación dada a Pedro de la Gasca en 1546, un testigo afirma que entre los soldados «hay muchos hombres que pretenden los gajes que

16 Aunque las fuentes no son claras sobre el papel de los curacas, es muy posible que los tenientes o capitanes hayan contactado a los curacas para organizar a la población indígena. Cieza anota que Alonso de Toro, primer teniente en Cuzco, hizo: «muy gran recaudo en tomar muy gran quantidad de carneros cargados de comida y todos los caciques principales de la provincia que fuesen con ellos...». Efraín Trelles mantiene una posición similar al analizar la encomienda de Lucas Martínez Vegazo (1991, p. 269). Por otro lado, puede que el cálculo político haya contribuido al apoyo de los curacas por parte de los encomenderos rebeldes, de manera similar al apoyo que, según señala Lamana, tuvo un inca títere como Paullu Inca (Lamana, 2008, p. 199). Futuras investigaciones permitirán ahondar más en este aspecto. 
de lo que Pizarro reporte por la tierra se dan y pretenden tener repartimientos por mano de Pizarro» (Pérez de Tudela, 1964, t. I, pp. 132-133). Nuevamente, aparece la figura del líder rebelde asociada al enriquecimiento personal. A juzgar por las fuentes, estos deseos de enriquecimiento parecen haber sido muy poco retribuidos, puesto que los mismos soldados habrían saqueado las localidades por donde pasaban, según se explicarás más adelante.

Esta extensa organización que implicó la participación de distintos sectores sociales, de indígenas y españoles, motivó una sensación de prosperidad inicial sobre el desarrollo de la rebelión. Al cabo de los dos primeros años, los rebeldes parecían imparables y la muerte del virrey era muestra de su fuerza y manejo de los recursos. En esos años, el entusiasmo era positivo y no faltaban las alabanzas al gobierno rebelde. El Palentino señala que «muchos había que se inclinaban a él, pareciéndole (inconsiderablemente) que aquel tiranizado señorío había de durar mucho tiempo, y que de ellos les podría resultar algún provecho, a lo menos, quedar en nombre de opinión de sus amigos y servidores» (Fernández, 1963, t. I, p. 54). Sin embargo, esta ilusión no duró demasiado y el panorama empezó a cambiar en el virreinato peruano.

\section{Los signos del colapso}

Entre 1547 y 1548 se manifestó con mayor claridad el desgaste de la riqueza a lo largo del virreinato en perjuicio de los principales aliados pizarristas. Gobernar un territorio era una labor muy distinta de conquistarlo (Céspedes, 1983, p. 93) y Gonzalo Pizarro y sus aliados, una vez acabado el primer conflicto contra Núńez Vela, demostraron poca capacidad para administrar el virreinato. Las fuentes revelan baja pro- 
ductividad, reducción demográfica, sensación de inseguridad entre los vecinos, saqueos en el territorio y destrucción general de los bienes materiales que existían. La suma de estas desgracias, asociadas a la continuidad de la rebelión, nos permite aproximarnos con mayor claridad al ocaso del movimiento rebelde.

Un primer aspecto a considerar es la situación de las encomiendas asociada al número de indígenas que en ellas estaban distribuidos. A mayor cantidad de indios, mayor tributo recibía el encomendero y mayor era el aporte que se destinaba al financiamiento de la rebelión. Los indios, además, eran quienes llenaban los tambos de alimentos, cargaban armas y ayudaban en la logística de los soldados durante el conflicto $^{17}$. Sin embargo, el colapso demográfico, resultado de las enfermedades y de la guerra, amenazaba trágicamente a los nativos del continente y con ellos también quedaba afectado todo el fruto de su trabajo. Es en el sector más numeroso del virreinato, pero el menos favorecido con el proceso de conquista, donde se empezó gestar el derrumbe de la rebelión.

En Charcas, la región que más tributos aportaba a la rebelión, las relaciones de repartos advierten el descenso en la cantidad de indios. La encomienda del teniente rebelde en la región, Francisco de Almendras, tenía originalmente 1200 indios, pero al final de la rebelión le quedaban solo 500 como consecuencia de «malos tratamientos que les hacia el dicho Francisco de Almendras e por las guerras con los chirigua-

17 La participación indígena estuvo presente desde la conquista de México hasta la del Perú y todavía queda por investigar más su aporte en el periodo temprano de la colonización. Para mayor información, véase el capítulo tres de Restall (2004). 
nes e por las de los españoles se han disminuido» (Loredo, 1940a, p. 56). Igualmente reportes de otras encomiendas de la región señalan el descenso de la población indígena.

La propia empresa pizarrista, en principio la más próspera del territorio, también fue afectada por este problema. La encomienda de Gonzalo Pizarro llegó a estar severamente golpeada puesto que «al tiempo que Felipe Gutiérrez fue a la entrada llevó setcientos indios i destos dicen no volvió ninguno» (Loredo, 1940a, p. 59), además de mencionarse que en la guerra «de cristianos» padecieron muchos indios. Una comunicación de Pedro de Soria, criado encargado de la encomienda de Hernando Pizarro, la más rica de la región, escrita en febrero de 1547, advertía que las entradas habían sido lo que más echaron a perder la producción y que más alborotaron la provincia. Asimismo, recomienda la pacificación del reino, ya que de esa forma la producción solo estaría destinada a la región y no se usaría para atender también los gastos de la guerra (Pérez de Tudela, 1964, p. 216). El análisis de Soria no solo señala la relevancia de este problema, sino que pone de manifiesto la asociación entre la guerra y la muerte indígena, que tuvo repercusiones centrales para la derrota del movimiento rebelde.

Sin embargo, sabemos que la conquista y las guerras civiles

126 no causaron la mayor cantidad de estragos entre la población nativa, sino la introducción de enfermedades. La referencia a las enfermedades apenas es mencionada un par de veces en las relaciones de repartimientos, pero debió tener un impacto masivo durante el periodo. Por ejemplo, la encomienda de Pablo de Meneses en Las Charcas tenía 900 indios, pero muchos murieron «de cierta enfermedad que les dio» (Loredo, 1940a, p. 53). 
Está bien establecido que las primeras décadas del periodo colonial fueron atroces para los habitantes locales, debido principalmente a la propagación de enfermedades y también a la violencia. David Cook afirma que las décadas de 1540 a 1560 fueron particularmente catastróficas, ya que a diferencia de los movimientos anteriores de la conquista y las guerras civiles durante la rebelión de Gonzalo Pizarro hubo «una mortandad impresionante» (Cook, 2010, p. 161). Además, de los castigos físicos a los que eran sometidos los indios, que justamente Las Leyes Nuevas buscaban limitar, y las mismas guerras, una epidemia de tifus en 1546 diezmó la población en gran número (Cook, 2010, p. 191). Respecto a la violencia, Assadourian plantea que además del fenómeno biológico, el extenso estado de conflicto durante los últimos años de los incas y primeros del colonialismo, incluida esta rebelión, tuvieron un impacto significativo en el despoblamiento indígena (1994, p. 40) Aunque las causas del despoblamiento han sido debatidas extensamente, no ha sucedido lo mismo con las consecuencias que tuvieron en la temprana sociedad colonial. La menor cantidad de indígenas en el territorio significó también una menor cantidad de trabajadores en las encomiendas $y$, por tanto, en la tributación y el sustento de la guerra, hecho que condicionó el resultado del conflicto.

En paralelo a la reducción de la población indígena, los reclamos por mejoras en la encomienda no dejaban de solicitarse a Pizarro. Pedro de Isásaga, administrador de una encomienda familiar en Charcas, escribió a su hermano para mencionarle que la cantidad de indios que poseía era muy reducida y planear una estrategia a fin de aumentar la posesión de sus encomendados (Pérez de Tudela, 1964, t. II, p. 27). Por la misma relación de repartimientos citada en Las Charcas, se sabe que su encomienda no producía «ningún maíz» y que 
El ocaso de los conquistadores: los límites de la riqueza y la lealtad durante la rebelión de los encomenderos en el virreinato del Perú, 1544-1548

"esta tierra es mui estéril y no se coge sino mui poca comida» (Loredo, 1940a, p. 55). Naturalmente, la principal preocupación de los encomenderos era proteger sus empresas y velar por una buena producción que les garantizara la riqueza que aspiraban perpetuar en el Nuevo Mundo. Cuando estas condiciones de deterioro empezaron a manifestarse, también la fidelidad al líder rebelde entró en cuestionamiento, de ahí que hacia el final del movimiento Isásaga decidió apoyar al bando de la Corona (Loredo, 1940a, p. 120).

La misma suerte corrieron otros personajes de la región. El general Pedro de Hinojosa, quien administraba la flota de la Mar del Sur, era encomendero también en Charcas, y el capitán Pablo de Meneses, cuyas encomiendas se vieron disminuidas como se ha señalado, se plegaron al bando del pacificador hacia 1547 en una coyuntura que coincidió con el deterioro de sus posesiones. En el primer caso, el descontento de Hinojosa fue clave para la victoria de De la Gasca, puesto que toda la flota rebelde pasó a ser utilizada contra el propio gobierno pizarrista y en ella se movilizaron las fuerzas que el pacificador iba reuniendo desde Tierra Firme. Ambos fueron muy bien premiados, ya que sus recompensas estuvieron entre las más grandes del reparto de Guaynarima (Loredo, 1940b, p. 118). Estos casos ponen de manifiesto los vínculos entre el deterioro de las condiciones materiales y la 128 deslealtad, aunque el desbande masivo será abordado en la siguiente sección.

Otro caso de deterioro de las encomiendas fue de uno de los principales aliados de Pizarro en Cuzco, Diego de Silva, encomendero que había capacitado a sus encomendados en la fabricación de armas al servicio de las tropas rebeldes. El caso de Silva demuestra que la guerra podía servir como un 
espacio para fomentar nuevas prácticas de trabajo entre la población indígena, hecho que se observa en la fabricación de armas por parte de indios «muchachos y maestros» de su encomienda (Pérez de Tudela 1964, t. I, p. 314) ${ }^{18}$. Sin embargo, a inicios de 1547, el encomendero alertó sobre los límites que sus servicios de indios armeros estaban alcanzando. Escribió que sus indios de Jauja "no han dado mas de veinte plateros y los de Guacora-Pacora otros veinte y, Amaya, diez» (Pérez de Tudela, 1964, t. I, p. 317), además de disculparse con Pizarro por incumplir una oferta mayor de entrega que realizó en una comunicación anterior.

Resulta que la comunicación de Silva fue sintomática del mal tiempo que atravesaba el valle de Jauja. En un documento de méritos y servicios de Cristóbal de Peña, fechado en 1548, se señala que "a causa de las alteraciones que a avido en estos dichos reinos los naturales dellos están fatigados e faltos de comida ${ }^{19}$. Nuevamente, la guerra aparece asociada al debilitamiento de la mano de obra indígena.

Al igual que en el caso de Las Charcas referido, estos signos de empobrecimiento estuvieron vinculados a los cambios de fidelidad de los actores involucrados. Uno de los encomenderos principales en Jauja era justamente Lorenzo de Aldana, lugarteniente de Gonzalo Pizarro en Lima, cuya encomienda debió ser afectada por el debilitamiento de la población indígena. A principios de 1547, Aldana viajó a Panamá, donde se entrevistó con el pacificador y decidió sumarse a su causa.

18 Por su parte, Lynch ha resaltado la importancia que existía en la fabricación de armas durante las guerras civiles (2001, p. 60.)

19 Méritos y servicios: Cristóbal Peńa: Perú, Sevilla, 1548, Archivo General de Indias, Patronato Real, 95B, R.8, folio 3. 
Al cruzar ambos eventos, propongo que esta decisión no fue solo resultado de la presión política que ejerció el pacificador sobre él, sino que Aldana era consciente del daño que recaía en su encomienda y, como su patrimonio era afectado, no tenía sentido mantenerse al lado de los rebeldes.

Un tercer caso del impacto que causó la guerra entre la población indígena nos remite a Trujillo, al norte del virreinato, donde estaba a cargo el teniente Diego de Mora. Primero, en diciembre de 1546, Mora se quejaba de que el maestre de campo Francisco de Carvajal había liberado a un asesino de indios en Pacasmayo (Pérez de Tudela, 1964, t. I, p. 163). Segundo, al soldado Francisco de Espinosa, por órdenes de Pizarro, se le encargó la labor de quemar y «despoblar» a los nativos en la región de Cajamarca, bajo administración de la ciudad de Trujillo, con el fin de tomar ganado e indios de servicio (De las Casas, 2003, pp. 279-280). Ambas referencias exponen el deterioro de la vida indígena, lo que sumado a la sensación de inseguridad que se expondrá en la siguiente sección, permiten entender el descontento y abandono de los vecinos a la causa rebelde.

A la larga, la guerra había resultado un mal negocio para los conquistadores y encomenderos, que aspiraban salir prósperos del conflicto. Gerónimo de Aliaga, encomendero en

130 Huaylas, se refugió en su encomienda para evitar involucrarse en el conflicto. Más adelante, se unió a De la Gasca cuando llegó a Lima y participó en la batalla de Jaquijahauana prestando sus indios en apoyo de los realistas para abastecer a las tropas con alimentos y cuyo resultado fue que se "comieron gran cantidad de maíz" y "más de setenta mil ovejas", 
hecho que dejó al conquistador "destruido y gastado" ${ }^{20}$. El caso muestra que la reclusión de Aliaga fue una estrategia para no afectar a sus indios y, por tanto, el patrimonio por el que había luchado durante el proceso de conquista, aunque finalmente el temor de empobrecerse a raíz de la guerra terminó por concretarse.

Gonzalo Pizarro, más preocupado en los asuntos de la guerra que en la administración del virreinato, perdió progresivamente la fuerza de trabajo que hacía de la encomienda un bien tan apreciado. En un memorial fechado en 1550, posterior a la rebelión, De la Gasca anotaba que la población natural del territorio estaba "disminuida» y agrega «esta tierra, tan poblada y llena dellos, ha quedado muy vacía, e por esto hay gran necesidad...» (Pérez de Tudela, 1964, t. II, p. 294). Ya que la distribución de la población indígena era central para sustentar el ejercicio del poder, su desaparición estuvo estrechamente ligada a la pérdida de liderazgo de Pizarro.

Estos signos de colapso también se generaron entre los soldados de menor rango del territorio y quedaron evidenciados en casos de saqueos. La expedición de Hernando de Bachicao, líder de la Armada del Sur, hacia Panamá, cuando aún el virrey estaba vivo, había cometido ataques y saqueos en contra de los aliados al virrey. Particularmente afectado se vio el capitán Santillana en el puerto de Manta. Según testigos, el saqueo incluyó el robo de comida, cofres de oro y plata, libros, pero muy en particular de indios y esclavos para el servicio de los propios rebeldes. Así mismo, se sabe que en $\mathrm{Pa}$ -

20 El caso de Aliaga y las citas extraídas de la probanza del conquistador son analizadas por Zuloaga (2012, p. 86). 
namá se dedicaron a la venta de "vasallos de su magestad» ${ }^{21}$, es decir, de indios. Lo saqueado responde precisamente a las expectativas materiales de los actores del periodo: dinero y mano de obra.

Desde la colonización en Tierra Firme eran comunes los excesos de los soldados pobres y se justificaba por el interés de la conquista (Góngora, 1962, p. 34); sin embargo, esta conducta se descontroló hacia 1548 como resultado de la falta de recursos. Primero, los afectados habían sido los indígenas no encomendados, pero con las guerras civiles estas conductas encontraron nuevos espacios en contra de los enemigos de turno. Durante la rebelión de los encomenderos, los saqueos se enfocaron inicialmente en los aliados del virrey, después ocurrieron también dentro del virreinato. Así lo expresa una ordenanza del momento, en la que se señala que los soldados no encontraban comida y se veían en la necesidad de «ranchear» a los indios y hacerles mucho daño (Lamana (2008, p. 222). Propongo entender estas conductas en contra de los indios como expresiones de desesperación por parte de los soldados que apuntaban obtener beneficios inmediatos frente a la crisis de recursos materiales.

Precisamente, una de las funciones de la entrega de encomiendas era evitar este tipo de conductas destructivas. Las

132 encomiendas tenían la función de reivindicar los intereses de los conquistadores, así como "disuadirlos de arrasar el país y avanzar en busca de más despojos” (Elliott, 2008, p. 78). El saqueo de los soldados mostraba que la posición de los rebeldes no conducía a una pacífica organización del territorio,

21 Excesos cometidos por Gonzalo Pizarro y sus capitanes: Perú, Sevilla, 1549, Archivo General de Indias, 185, R.13, folio 6r. 
donde los actores pudieran prosperar, sino que seguía el camino opuesto. La diferencia es que esta vez los afectados eran los mismos habitantes del territorio, que debían sustentar los ingresos de la guerra.

Los primeros en reaccionar ante esta contradicción fueron los vecinos de Panamá. Aunque inicialmente habían mostrado interés en dialogar con Bachicao y los representantes pizarristas, la actuación destructiva de los rebeldes generó la oposición del cabildo de la ciudad e incluso el apoyo desde Nicaragua y se opusieron y resistieron a Bachicao. Cuando el pacificador Pedro de la Gasca llegó a la ciudad a inicios de 1546, la ciudad le ofreció apoyo a su causa. Similar conducta se tomó progresivamente en el virreinato peruano.

De esta manera, los recursos materiales asociados a la población indígena y a los ingresos estaban en decadencia hacia los últimos años de la rebelión. Por un lado, las encomiendas presentaban una gran mortandad que afectaba la producción, sea como resultado de la acción de la guerra o por las enfermedades que arrasaron el virreinato, mientras que los aliados afectados fueron replanteando su fidelidad al movimiento rebelde. Por otro lado, los saqueos en el territorio también eran una muestra de la desesperación por obtener recursos y de la poca capacidad de Pizarro para brindarlos. A continuación, se expondrá cómo los signos del colapso que anunciaban el fracaso de la rebelión derivaron en la derrota del movimiento.

\section{De la crisis a la deserción general}

Hacia el segundo periodo de la rebelión, entre 1547 y 1548, la guerra parecía salirse de las manos de Gonzalo Pizarro y 
de sus tenientes. En las distintas ciudades del virreinato había muestras de descontento entre los vecinos-encomenderos por las decisiones que tomaban su líder y sus tenientes. La distribución de la riqueza, la defensa de los vecinos y el ejercicio de la justicia son tres temas centrales que ponen de manifiesto el creciente rechazo a la autoridad rebelde en un contexto de deterioro material en el virreinato.

El primer caso se desarrolló en Arequipa, donde crecía la sensación de inseguridad en torno a la guerra. El teniente de la ciudad, Lucas Martínez Vegazo, comunicó a Gonzalo Pizarro en 1547 que los vecinos estaban sin armas, porque se las sustrajeron para enviárselas (Barriga, 1955, t. I, p. 164). La situación generó una sensación de desamparo, por lo que Martínez Vegazo suplicó que las armas fueran enviadas de regreso a los vecinos. La inseguridad que anunciaba el teniente no era extrańa si consideramos que Diego Centeno se había alzado en favor de la Corona en el altiplano ese mismo año y que el propio Martínez Vegazo sufrió la usurpación de su encomienda en Tarapacá por parte de Ulloa ${ }^{22}$, por lo que los vecinos podían sentirse inminentemente atacados.

La falta de armamento fue un reclamo estrechamente vinculado a la defensa del patrimonio personal de los encomenderos. Al carecer de armas, se veían imposibilitados de defender

134 sus posesiones ante un eventual ataque y el propio teniente era incapaz de ejercer justicia sin ellas. En una siguiente comunicación, Martínez Vegazo volvió a pedir al líder rebelde que defendiera su encomienda, la cual mencionaba valer más que toda la gobernación de Chile (Barriga, 1955, t. I,

22 En la misma carta que pedía el regreso de las armas, Martínez Vegazo también pidió atender el robo de su encomienda en Tarapacá. 
p. 169). Ulloa había destruido su repartimiento y se había trasladado a Arica, mientras que el teniente debía quedarse en la ciudad de Arequipa a la espera de nuevas órdenes. La falta de armas ante una amenaza real era un asunto central en la defensa de los intereses de los encomenderos.

El escenario se tornaba cada vez peor. Martínez Vegazo comunicó a Gonzalo Pizarro que en la ciudad no había comida y que los precios se habían elevado (Barriga 1955, t. I, p. 164). Pero el líder, más interesado en su situación militar ante las noticias de la llegada del pacificador De la Gasca, pidió que su teniente preparara soldados para partir hacia Lima bajo pena de muerte o pérdida de bienes (Trelles, 1991, p. 75). Sin posibilidades de defenderse de cualquier amenaza y con el peligro de quedarse sin bienes para sustentarse, a los vecinos solo les quedó darle la espalda al teniente de turno. Apresaron a Martínez Vegazo y lo relevaron de sus funciones. Con ello, Gonzalo Pizarro perdió aliados en el sur del virreinato.

Otra ciudad que concentró similares preocupaciones fue Trujillo, donde su teniente, Diego de Mora, advirtió sobre la precaria situación de los vecinos. En noviembre de 1546 reclamó que no tenían cómo defenderse: «aquí no hay gente de guerra, los que hay son los vecinos que vuestra señoría sabe, y habrá de quince o veinte oficiales y mercaderes» (Pérez de Tudela, 1964, t. I, p. 161). De manera parecida a la situación de Arequipa, la incapacidad de defenderse era una preocupación central, en vista de que los enemigos podían llegar eventualmente y arrebatar sus posesiones. Pese a los inconvenientes, Mora continuó su labor de apoyo a la rebelión y en marzo de 1547 escribió a Gonzalo Pizarro para comunicarle que hizo una derrama para recaudar fondos para 
la guerra y que, de ser necesario, iba a tomar el dinero de la caja real . Sin embargo, frente a la inminente llegada de De la Gasca y la desatención de su líder, las posiciones de lealtad cambiaron, ya que al poco tiempo el propio Diego de Mora encabezó la traición de distintos vecinos, con los cuales zarpó hacia el lado del pacificador De la Gasca en Tierra Firme (De las Casas 2003, p. 271).

Los intentos de Gonzalo Pizarro por recuperar el control de Trujillo fueron vanos. García de León fue nombrado nuevo teniente de la ciudad y como parte de sus indicaciones figuraba repartir la riqueza de Diego de Mora y asegurar la posesión de los indios de los vecinos restantes (Loredo, 1943, pp. 70-71). Estas medidas buscaban subsanar aquellos puntos débiles que habían dejado insatisfechos a los vecinos y que promovían el abandono de la causa rebelde. La promesa de repartir indios aparecía nuevamente dentro de estas indicaciones y, como fue desde inicios de la conquista, funcionaba como mecanismo de fidelidad. El esfuerzo fue nuevamente improductivo. Así como Diego de Mora desistió de la causa rebelde, otros encomenderos de la zona siguieron su camino. Tal es el caso de Gómez de Solís, uno de los encomenderos más ricos de la región, quien en medio de esta situación se sumó al bando de De la Gasca, a juzgar por el hecho de que su nombre figura en el reparto de Guaynarima (Lore136 do, 1940b, p. 118). Su cambio de bando debió partir de la misma decepción frente al gobierno pizarrista que hizo que Mora y otros vecinos tomaran el camino de la traición.

La región de Las Charcas permite analizar cómo el cambio de las condiciones económicas de la encomienda impactaba en la fidelidad de los encomenderos. En esa región, que sustentaba su riqueza en el trabajo de la densa población indígena 
que concentraba, se descubrió la mina de Potosí al inicio de la rebelión y con ello cambiaron las expectativas materiales de la zona. Hacia el final del movimiento, esa región se estaba convirtiendo en un foco de atención de los encomenderos de la zona, quienes empezaron a desear su promoción social a partir de la minería y no de la encomienda tradicional, la cual, como se ha mencionado, sufría un deterioro demográfico significativo. Para ello, conviene analizar la situación de la región y el trágico destino del teniente de la ciudad, Francisco de Almendras.

En Las Charcas estaban las encomiendas más ricas del territorio y por ello su aporte económico al movimiento era importante (Loredo, 1940b, pp. 53-58). Muchos indios fueron enviados para la extracción de minerales y el interés de los distintos encomenderos y potenciales comerciantes empezaba a concentrarse en esa región. Por ejemplo, Martínez Vegazo comunicaba en una carta a Gonzalo Pizarro que por culpa de la minería en el altiplano, la ciudad de Arequipa se estaba desabasteciendo de alimentos (Barriga, 1955, t. I, p. 164). El fenómeno escapaba a los planteamientos de organización social del gobernador Pizarro y ningún teniente recibió indicación alguna para administrar esta actividad.

Surgió, entonces, en plena rebelión la posibilidad de enriquecerse sin entrar en contacto con el gobernador o algún intermediario para obtener mayores pagos o encomiendas. La actividad minera creó un nuevo horizonte de expectativas materiales, pue los ingresos de la extracción minera eran mucho más rentables que la espera de favores por parte de los líderes de la rebelión en un contexto de guerra entre rebeldes y autoridades de la Corona que no estaba generando ningún beneficio a los vecinos. Agustín de Zárate, testigo contempo- 
ráneo, relata que en esa región los precios de los costales de coca y de las fanegas de maíz eran elevados, y que distintas empresas habían cesado para enfocarse en la actividad minera (Zárate, 1995, pp. 228-229). En suma, los vecinos se concentraron en el trabajo de la mina y dejaron de lado su interés en el conflicto.

Sin embargo, el principal obstáculo para el enriquecimiento de los vecinos con la minería era Francisco de Almendras, teniente de la ciudad de La Plata. Como parte de sus funciones, Almendras pedía tributos para sustentar a las fuerzas rebeldes y esto generó un gran descontento entre los encomenderos locales, quienes conspiraron contra él. A ello debe sumarse la crisis demográfica tratada anteriormente y que debió ahondar la idea de que el gobierno rebelde era pernicioso para los intereses de los vecinos. El resultado fue un movimiento conspiratorio que le costó la vida al teniente rebelde en Las Charcas y que redirigió el apoyo de los encomenderos hacia las fuerzas de Diego Centeno, quien luchaba en nombre del rey hacia 1547 . Es entonces que la actividad minera se reveló como un aliciente para retornar al apoyo del bando de la Corona.

La pérdida de Las Charcas implicaba la pérdida de tributos de la región más rica del territorio. La respuesta pizarrista no 138 se hizo esperar y Francisco de Carvajal, maestre de campo, fue enviado para retomar la ciudad y a Centeno, tal cual hizo Almendras en su momento, quien debió recoger tributo para financiar su defensa. Este nuevo enfrentamiento mantuvo en riesgo a los vecinos, que seguían sin obtener la estabilidad y paz que requerían para enfocarse en el trabajo minero. El temor se apoderó de los vecinos, a juzgar por la actuación de personajes como Pedro del Río, quien a mediados de 1547 
huyó con sus indios y alimentos del valle del Collao (Pérez de Tudela, 1964, t. II, p. 19). No era el único indicador de la preocupante situación de esa región. Desde el Cusco, Alonso de Toro decidió formar una tropa y perseguir a Diego Centeno; sin embargo, debió retroceder hasta su ciudad debido a la falta de alimentos y "por estar los caciques principales con el capitán Diego Centeno y la tierra alçada» (Cieza de León, 1991, pp. 218-219). La expresión "tierra alzada" es común entre los cronistas para referirse a la hostilidad de las poblaciones nativas contra los soldados espańoles. Puede que el apoyo de los curacas a Centeno se diera en un clima de hostilidad hacia el gobierno rebelde generado por la precariedad de las condiciones de vida de los indios, que las guerras y las enfermedades trajeron a la región. Tal cual lo hacían los vecinos, los curacas también se pusieron en contra de Pizarro y sus representantes.

La presencia de Carvajal en el altiplano solo ahondó los problemas. Aunque se retomó efímeramente Las Charcas luego de la batalla de Huarina, el territorio fue nuevamente exprimido por Carvajal para financiar las tropas contra el recién llegado pacificador Pedro de la Gasca. Ante esta situación, Carvajal, como teniente provisional del lugar, recaudó nuevamente fondos calculados en setecientos pesos y llevó consigo diez mil carneros cargados de comida (Zárate, 1995, pp. 228-229). Su incursión fue más parecida al saqueo de un pueblo vencido que a la justa distribución de los recursos que debía realizar. Según narra Zárate, luego de referirse a la gestión de Carvajal, los soldados tentaron la posibilidad de matarlo por no haberles beneficiado.

La conexión entre las autoridades del gobierno y la región altiplánica fue breve. Carvajal tuvo que volver inmediatamente 
al lado del caudillo con lo obtenido en su campaña en Las Charcas. Llevó lo que quedaba de riqueza en la ciudad y la aversión contra las autoridades rebeldes debió cobrar mayor vigor entre los pobladores de la región.

Gonzalo Pizarro era consciente de las traiciones, aunque sus decisiones siguieron entorpeciendo su gestión. Una relación del momento seńala el temor del líder rebelde sobre la llegada en barco de Pedro de la Gasca a la Ciudad de Los Reyes y que este ganara la lealtad de la población, razón por la cual planeó su retirada de la ciudad. Esto no era extraño, pue en el virreinato peruano se sabía de las traiciones de sus capitanes en Panamá a inicios de 1547. La fuente agrega que «se buscaban yeguas y se encalgaban soldados con mucha diligencia» ${ }^{23}$. Una comunicación posterior de De la Gasca precisa que Juan de Acosta, capitán leal a Pizarro, tomó 1500 caballos, yeguas y mulas, así como el oro y plata de distintos mercaderes para trasladarlos al Cusco (Pérez de Tudela 1964, t. II, p. 232). Lejos de respetar los procedimientos de colaboración que se realizaron anteriormente para financiar la guerra, los vecinos fueron forzados a abandonar sus bienes.

La capital del virreinato era entonces una ciudad sumida en el caos. Los libros del cabildo limeño señalan que a fines de 1545 e inicios de 1546 la ciudad de Lima estaba en "un 140 verdadero estado de emergencia» (Moya, 1985, pp. 37-38). Dice el acta de cabildo que los negros y cimarrones estaban robando en los caminos y atacando las «estancias» de los naturales. Los ataques continuaron y se discutía con urgencia la necesidad de implementar alguaciles que protegieran a los

23 Causa contra Gonzalo Pizarro: alteraciones en Perú, Sevilla, 1547, Archivo General de Indias, Patronato Real, 90B, N.1, R.39, folio 8r. 
indios de los españoles (Moya, 1985, p. 42). Es en este clima de destrucción que la presencia del gobernador no revirtió la situación, sino que la ahondó al llevarse los recursos de la ciudad.

Al hilar estos acontecimientos, no es difícil entender por qué la capital se plegó automáticamente al bando de De la Gasca cuando este llegó. Las obligaciones de liderazgo, basadas en garantizar la seguridad material y la defensa contra las amenazas que atenten contra la prosperidad material ${ }^{24}$, se veían largamente incumplidas. Esto repercutió negativamente en la imagen de autoridad de Gonzalo Pizarro y la deserción se consolidó como la opción más viable.

La pérdida de la ciudad de Los Reyes, junto a las otras ciudades mencionadas en esta sección, tuvo grandes implicancias para la derrota rebelde ya que concentraban la mayor parte de encomiendas. Según información recogida por José de la Puente, en Lima había 28 encomiendas en 1550, en Arequipa 29, en Trujillo 31 (1991, p. 141), mientras que en Charcas había alrededor de 28, pero de gran valor (Loredo 1949a, pp. 51-62). Estas ciudades concentraban la gran mayoría de encomiendas del territorio y en todas ellas hubo movimientos en contra del gobierno rebelde, que terminaron por abandonar su causa.

De igual forma, otros soldados menores pasaron de la desilusión a la deserción en favor de la Corona. Alonso de Borregán declaró en su crónica que se encontraba esperando a Vazques

24 Moore ha sostenido que el ejercicio del liderazgo involucra esas funciones centrales. Considero que su análisis es oportuno para comprender a los actores que participaron durante la rebelión. Véase Moore (1989, p. 34). 
de Cepeda, uno de los líderes rebeldes cercanos a Pizarro, "para que me hiciese tornar dozientos pesos que un tirano corregidor bartolome de Villalobos que allí estaba fui a pedírselos al tirano Gonzalo Pizarro y nunca pude alcanzar que cada dia me pelaban y robaban lo que tenia por no querer seguir su opinión» (Borregán, 1968, t. II, p. 463). Borregán no encontró justicia en el bando rebelde para reparar el dinero que pedía, que era una de las humildes aspiraciones que tenían muchos soldados como él, y su descontento le llevó a oponerse a los planes del caudillo rebelde como luego relata.

El hambre diezmaba también a otros soldados, que abandonaban la causa rebelde. Cieza cuenta que antes del encuentro con «el Pacificador", había soldados que se fugaron porque no «hallaron cosa alguna que comer» y que sus caballos «no comían ni reposaban, yvan tan cansados y fatigados que no les podían llevar» (Cieza de León, 1991, p. 648). El desbande ocurrió progresivamente y se aceleró con la presencia del representante de la Corona. Si a esto sumamos los saqueos dentro del virreinato y a otras ciudades del continente, puede notarse que la situación del gobierno en el Perú no había mejorado; por el contrario, estaba involucionando hacia las conductas de la primera fase de la conquista americana, en la que la supervivencia era una necesidad prioritaria. Esto explica la pobre posición de Gonzalo Pizarro para mantener su ejército

142 y el descalabro que significó la batalla de Jaquijahuana.

\section{El ocaso de los conquistadores}

La actuación de Pedro de la Gasca, contraria a la de Gonzalo Pizarro, logró atender y responder a las principales preocupaciones de los rebeldes que desertaron del bando pizarrista. El agente de la Corona estuvo muy preocupado en no alterar 
los intereses de los vecinos, para quienes el sustento de sus privilegios y de sus indios encomendados era una prioridad. Diego Fernández, El Palentino, relata que a su llegada a Quito el pacificador escribió a Pedro de Salazar, a Benalcázar y a Almendáriz para que le enviaran como soldados gente «de su voluntad» $\mathrm{y}$ "que no hiciese falta en las granjerías ni defensa de sus gobernaciones» (Fernández, 1963, t. I, p. 211). La actitud cauta del pacificador le permitió construir alianzas a su favor para sustentar su guerra en el virreinato peruano.

La estrategia de De la Gasca y su éxito en el territorio del virreinato peruano confirmó los planes de la Corona para controlar a sus lejanas colonias. Feros ha señalado que entre mediados del siglo XVI y hasta 1660 la Corona de Castilla no trató de eliminar las redes de alianzas, sino usarlas en su propio beneficio (1998, p. 36). En efecto, la estrategia de De la Gasca fue atraer a los insatisfechos aliados de la rebelión (encomenderos, vecinos y conquistadores) y debilitar la posición de los rebeldes, la cual, como he mostrado, estaba bastante debilitada. Para ello, ofreció aquello que Gonzalo Pizarro no podía garantizar: dar seguridad material y un entorno pacífico donde arraigar y prosperar. Un traslado del mensaje que envió De la Gasca al virreinato peruano expresa el deseo de llevar "paz y sosiego y de quitarles la inquietud y desventura que tan a costa de vidas en ese reino ha habido" (Fernández, 1963, t. I, p. 166).

Como se ha señalado, la ineficacia de los tenientes para velar por los intereses de los encomenderos y vecinos de las principales ciudades del virreinato derivó en la pérdida de confianza de la autoridad pizarrista y, como consecuencia, se fortaleció la autoridad real. Este reconocimiento a la Corona y sus autoridades fue importante para asentar las institucio- 
nes coloniales y construir una burocracia, que impidió el desarrollo de nuevos poderes locales y, por tanto, evitó nuevas rebeliones (Pietschmann, 1989, pp. 182-183). El resultado del conflicto demostró que los intentos de rebelión eran estériles, puesto que solo bajo la autoridad de la Corona se podía establecer una organización social que velara por los intereses de sus protagonistas.

Este conjunto de referencias al empobrecimiento de las condiciones materiales permite sostener que la rebelión solo se pudo sustentar mientras duró la riqueza. Pietschmann ha señalado que «los acontecimientos en el Perú también ponen en evidencia que no existía alternativa ideológica ni política a la autoridad de la Corona» (1989, p. 183). En efecto, durante los años que duró la rebelión nunca se articuló un proyecto que permitiese afrontar la crisis material y construir una verdadera burocracia alrededor del gobernador. El ligero intento por coronar a Gonzalo Pizarro solo fueron expresiones radicales del descontento con la Corona, pero no síntomas de la consolidación de una clase dominante local. Pizarro, como gobernador, solo mantuvo su autoridad mientras tuvo recursos, cuando los perdió, ya no tenía donde asir su poder.

Entender el resultado de la rebelión a partir de su desarrollo interno permite introducir reflexiones interesantes sobre

144 la vida temprana colonial. En primer lugar, los actores del momento no respondían horizontalmente a las órdenes impartidas por sus autoridades y menos a las emanadas por la Corona, por el contrario, calculaban individualmente o en grupos qué decisiones tomar y apostaban por el bando que ofreciera mejores beneficios. En segundo lugar, el fracaso de la rebelión estuvo estrechamente relacionado al deterioro de las encomiendas, esto es, al desgaste de la población indíge- 
na, quienes estaban en la parte más baja de la pirámide social, pero cuya silenciosa actuación minó los recursos de la rebelión y con ello la fidelidad de los encomenderos. Finalmente, la rebelión demostró que los conquistadores fueron incapaces de construir un gobierno que organizara y administrara el virreinato, pese a los intentos que realizaron en esos cuatro años ${ }^{25}$.

La rebelión había arruinado a muchos tenientes y sus fortunas construidas durante la conquista. En 1548, se derrumbaba una lógica de distribución de la riqueza en torno a la figura del gobernador, que había permitido a los conquistadores administrar el territorio con gran autonomía. Desde 1532, la presencia del estado colonial fue muy débil en el territorio del Perú, lo que posibilitó el empoderamiento del gobernador de turno y de sus principales aliados, varios de los cuales alcanzaron el techo de su carrera hasta 1548. La presencia de Blasco Núñez Vela y de Pedro de la Gasca tenía como objetivo asentar el poder real en el virreinato y restar autoridad a los conquistadores y encomenderos, hecho que generó la rebelión. La derrota de los rebeldes implicó una conquista institucional del virreinato, puesto que luego de 1548 y bajo supervisión de De la Gasca se instalaron las instituciones coloniales centrales como la Audiencia, la Iglesia y, poste-

25 Gonzalo Pizarro escribió una carta al rey donde defendía sus medidas como gobernador por el bien del virreinato y que cumplía con el fin evangelizador de la conquista: "procurando que los naturales rescibiesen la religión cristiana, y compeliendo a los vecinos de la tierra que en todos los repartimientos toviesen sacerdotes que doctrinasen los naturales, cosa que hasta mi tiempo no se había hecho" (Pérez de Tudela, 1964, t. I, p. 367). La comunicación muestra sus intentos de mostrarse como un buen gobernante capaz de cumplir los objetivos que justificaban la conquista. 
riormente, la figura del virrey, y se reguló la administración del territorio. A los conquistadores restantes solo les quedó someterse a la autoridad real y quedar aislados progresivamente. En 1560 este proceso ya estaba avanzado, pues solo la mitad de los encomenderos se mantenían desde la conquista y el resto eran nuevos (Lockhart, 1982, pp. 26-27).

Como esta investigación ha puesto de manifiesto, la administración de los recursos fue un tema de relevancia central durante la temprana colonización. En el caso peruano, una buena o mala gestión podía comprometer alianzas y resultados de guerras durante los primeros años de conflictos civiles, como el caso de la rebelión de los encomenderos demuestra. El empobrecimiento de las encomiendas pertenecientes a los principales aliados pizarristas y la pérdida de los indios encomendados estuvieron directamente relacionados con la menor capacidad logística del movimiento, la disminución de los ingresos y la pérdida de confianza de sus aliados. Este último punto fue central, pues ante los mayores signos de pobreza y falta de control por parte de Pizarro y sus tenientes, los vecinos y encomenderos de las ciudades fueron abandonando su causa. Como se ha visto, el impacto del empobrecimiento del virreinato fue sentido incluso por los soldados de menor categoría. Todos estos factores minaron la fidelidad que existía al gobernador Pizarro hasta su derrota final en 1461548.

La derrota de los encomenderos rebeldes y su líder demostró que la Corona era la única que podía ofrecer una organización eficiente en el nuevo espacio colonial. La administración de los grandes recursos del virreinato peruano y su población residente fue compleja y requería un esfuerzo y pericia que los conquistaron no podían ofrecer, pero sí las autoridades 
coloniales. Por mucho tiempo, ningún otro gran movimiento pudo articularse en contra de las autoridades coloniales hasta la rebelión de Túpac Amaru II a fines del siglo XVIII.

Recibido: 25 de octubre del 2018

Aprobado: 15 de abril del 2019

\section{Referencias bibliográficas}

Assadourian, C. S.

(1994)

Transiciones hacia el sistema colonial andino. Lima:

Instituto de Estudios Peruanos, El Colegio de México.

Bakewell, P.

(1989) La maduración del gobierno del Perú. Historia de México, 39 (1), 41-70.

Barriga, V.

(1955) Documentos para la historia de Arequipa (t. I). Arequipa: Editorial La Colmena.

Bataillon, $\mathrm{M}$.

La colonia: ensayos peruanistas. Lima: Universidad Nacional Mayor de San Marcos.

Borregán, A.

(1968) Crónica de la conquista del Perú (t. II). Lima: Editores Técnicos Asociados.

Casas, M. de las

(2003) Relación de las cosas acaecidas en las alternaciones del Perú después que Blasco Núñez Vela entró en él. Lima: Pontificia Universidad Católica del Perú. 
El ocaso de los conquistadores: los límites de la riqueza y la lealtad durante la rebelión de los encomenderos en el virreinato del Perú, 1544-1548

Céspedes, G.

(1983) América hispánica (1492-1898). Barcelona: Labor.

Chaunu, P.

(1973) Conquista y explotación de los nuevos mundos (siglo XVI). Barcelona: Labor.

Cieza de León, P.

(1991 Crónica del Perú: Cuarta parte. Lima: Pontificia Universidad Católica del Perú, Academia Nacional de la Historia.

Cook, N.

(2010) La catástrofe demográfica andina: Perú 1520-1620.

Lima: Pontificia Universidad Católica del Perú.

Drigo, A. L.

(2006)

La gran rebelión de Gonzalo Pizarro: liderazgo y legitimidad. Buenos Aires: Dunken.

Elliott, J.

(1990) La conquista española y las colonias de América. En L. Bethell (Ed.), Historia de América Latina (vol. I, pp. 127-169). Barcelona.

Elliott, J.

(2008) Imperios del mundo atlántico: España y Gran Bretaña en América (1492-1830). México: Taurus.

Fernández, D.

148 (1963) Quinquenarios o historia de las guerras civiles del Perú (t. I y II). En, J. Pérez de Tudela (Ed.). Crónicas del Perú. Madrid: Atlas.

Feros, A.

(1998) Clientelismo y poder monárquico en la España de los siglos XVI y XVII. Relaciones, 19 (73), 17-49. 
Gutiérrez de Santa Clara, P.

(1963) Historia de las Guerras Civiles del Perú. En Pérez de Tudela, Juan (ed.) Crónicas del Perú. Madrid: Atlas.

Góngora, $M$.

(1962) Los grupos de conquistadores en Tierra Firme (15091530). Santiago de Chile: Universidad de Chile.

Hamnett, B.

(2001) Historia de México. Madrid: Cambridge University Press.

Lamana, G.

(2008)

Domination without dominance: Inca-Spanish encounters in early colonial Peru. Durham: Duke University Press. https://doi.org/10.1215/9780822388715

Lockhart, J.

(1982) El mundo hispanoperuano, 1532-1560. Ciudad de México: Fondo de Cultura Económica.

Lohmann, G.

(1977) Las ideas jurídico-politicas en la rebelión de Gonzalo Pizarro. Valladolid: Casa Museo de Colón, Seminario Americanista.

Loredo, R.

(1940a) Relaciones de repartimientos que existían en el Perú al finalizar la rebelión de Gonzalo Pizarro. Revista de la Universidad Católica t. 8 (1),51-62.

Loredo, R.

(1940b) El reparto de Guaynarima. Revista Histórica t. 13, 78124.

Loredo, R.

Alardes y derramas. Lima: Gil. 
El ocaso de los conquistadores: los límites de la riqueza y la lealtad durante la rebelión de los encomenderos en el virreinato del Perú, 1544-1548

Loredo, R.

(1943) Documentos desdeñados. Revista Histórica, t. 16, 58-77.

Loredo, R.

(1958) Los repartos. Lima: D. Miranda.

Lynch, J.

(2001) América Latina, entre colonia y nación. Barcelona: Crítica.

Moore, B.

(1985) La injusticia: bases sociales de la obediencia y la rebelión. México, D.F.: Universidad Nacional Autónoma de México.

Moya, F.

(1985)

Lima, el cabildo y la vida local en el siglo XVI (15341553). Santo Domingo: Corripio.

Pérez de Tudela, J.

(1964) Documentos relativos a Don Pedro de la Gasca y a Gonzalo Pizarro (t. I y II). Madrid: Real Academia de Historia.

Pietschmann, $\mathrm{H}$.

(1989) El Estado y su evolución al principio de la colonización de América. Ciudad de México: Fondo de Cultura Económica.

150 Puente Brünke, José de la

(1991) Encomienda y encomenderos en el Perú: estudio socialy politico de una institución. Sevilla: Excma. Diputación Provincial de Sevilla.

Restall, M.

(2004) Seven myths of the Spanish conquest. New York: Oxford University Press. 
Rivera, R.

(1996) Libro del cabildo de la ciudad de San Juan de la Frontera. Lima: Casa de la Cultura del Perú.

Seed, P.

Ceremonies of possession in Europe's conquest of the new world, 1492-1640. New York: Cambridge University Press.

Thorton, J.

A cultural history of the Atlantic World, 1250-1820. Nueva York: Cambridge University Press.

Trelles, E.

Lucas Martínez Vegazo: funcionamiento de una encomienda peruana inicial. Lima: Pontificia Universidad Católica del Perú.

Varón, R.

La ilusión del poder: apogeo y decadencia de los Pizarro en la conquista del Perú. Lima: Instituto de Estudios Peruanos, Instituto Francés de Estudios Andinos.

Zárate, A. de

(1995) Historia del descubrimiento y conquista del Perú. Lima: Pontificia Universidad Católica del Perú.

Zuloaga, M.

(2012)

La conquista negociada: guarangas, autoridades locales e imperio Huaylas, Perú (1532-1610). Lima: Instituto de Estudios Peruanos, Instituto Francés de Estudios Andinos. 